\title{
New distributional record of Anthrenus dorsatus Mulsant \& Rey, 1868 (Coleoptera, Dermestidae), Thessaloniki, Greece
}

\author{
Graham J. Holloway', Dimitrios E. Bakaloudis² \\ 1 Centre for Wildlife Assessment and Conservation, School of Biological Sciences, The University of Reading, Reading, UK RG6 2AS. 2 Aristotle \\ University of Thessaloniki, School of Forestry and Natural Environment, PO Box 241, University Campus, 54124 , Thessaloniki, Greece. \\ Corresponding author: Graham J. Holloway, g.j.holloway@reading.ac.uk
}

\begin{abstract}
Anthrenus dorsatus Mulsant \& Rey, 1868 has been recorded from North Africa, Malta, and Iberia. During a recent visit to Thessaloniki, Greece, several Anthrenus species were collected, including A. dorsatus. The previously known distribution of $A$. dorsatus suggested that this species was restricted to the western Mediterranean basin, possibly with a coastal bias. This record extends the known range of $A$. dorsatus farther east and providing more evidence of range expansion in the pimpinellae species group across Europe, possibly driven by global climate change.
\end{abstract}

\section{Keywords}

Aedeagus, antenna, Anthrenus pimpinellae, bursa copula, climate change, sternite IX.

\section{Introduction}

The family Dermestidae has been the subject of intense, mostly museum-based, study in recent years (Háva 2015a). As a result of this work, the number of described species of Dermestidae has increased rapidly to over 1,600. The genus Anthrenus Geoffroy, 1762 belongs to this family. It is a highly speciose taxon containing over 200 species (Háva 2015a) split into 10 subgenera. Recognition of the genus Anthrenus is generally straightforward; nevertheless, the numbers of species in some of the subgenera remain poorly known and new species continue to be described.

A group containing some of the most difficult species to differentiate belong to the subgenus Anthrenus (Anthrenus) spp., notably the A. pimpinellae complex. Kadej et al. (2007), supplemented by Kadej and Háva
(2011), carried out a review of the Palaearctic species of the A. pimpinellae species group. Later Holloway (2019) added an additional species, bringing the total number of Palaearctic species in this group to 21 (including one species having two subspecies). Many of these species are currently differentiated largely on genitalia and antennal structure. Since good field identification characters have not yet been described, rather little is known about distribution and ecology of these species. Recent field-based work extending our knowledge of $\mathrm{A}$. pimpinellae complex species is rare but includes that of Holloway (2019) and Holloway et al. (2019).

Anthrenus dorsatus Mulsant \& Rey 1868 is a member of the A. pimpinellae complex. This species has been noted from Algeria (Háva 2003), Libya (Háva and Herrmann 2009), Tunisia (Háva 2015b), Morocco (Háva 2015c), Malta (Háva and Mifsud 2006), and Mallorca 
(Holloway et al. 2019). Anthrenus dorsatus very closely resembles $A$. goliath Mulsant \& Rey, 1868 (Kadej et al. 2007), a species reported to have a much wider distribution than A. dorsatus. Anthrenus goliath is thought to be distributed through southern Europe, around the eastern Mediterranean, into North Africa, and throughout eastern Europe (Háva 2015a). Both A. dorsatus and $A$. goliath were considered to be subspecies of $A$. pimpinellae by past authors (e.g. Mroczkowski 1968). Anthrenus dorsatus was raised to specific status by Háva (2003), but more work needs to be carried out to establish better ways of differentiating between the two species. Here we document a new record for Anthrenus dorsatus which extends the known distribution east through the Mediterranean region to include Greece.

\section{Methods}

Dermestidae were collected from the field from Thessaloniki and the immediate vicinity on 6-8 May 2019 (Fig. 1). Specimens were collected from white flowers, in particular Hemlock (Conium maculatum L.) and Hoary Cress (Lepidium draba L.). Dermestidae were knocked from the flowers into a plastic tray to facilitate aspiration using a pooter. Species were separated in the laboratory using the descriptions provided by Kadej et al. (2007) and confirmed by comparisons with images in Holloway et al. (2019). All individuals collected were stored in $2 \%$ acetic acid until dissection under a Brunel BMSL zoom stereo LED microscope. Identification was based on antennal, aedeagus, and sternite IX structure. Images were taken using a Canon EOS 1300D and fed through
Helicon Focus 6-Pro focus stacking software. Habitus images were captured at $\times 20$ and antennae images were captured at $\times 63$. Images of sternite IX, aedeagus and bursa copula were captured at $\times 100$ using a Brunel monocular SP28 microscope. Morphometrics were taken using DsCap.Ink software. Voucher specimens are lodged with the Natural History Museum, London (BNHM) and GJH private collection (GJHPC).

\section{Results}

New records of Anthrenus dorsatus. Greece - Kedrinos Lofos, Thessaloniki $\left(40^{\circ} 38^{\prime} 16.26^{\prime \prime} \mathrm{N}, 022^{\circ} 57^{\prime} 54.67^{\prime \prime} \mathrm{E}\right)$, 6 May 2019 G.J. Holloway \& D.E. Bakaloudis leg., 2 males (Fig. 2) and 2 females - Perea $\left(40^{\circ} 29^{\prime} 56.01^{\prime \prime} \mathrm{N}\right.$, 022 53'14.25"E), 7 May 2019 G.J. Holloway \& D.E Bakaloudis leg., 1 male - Sindos $\left(40^{\circ} 39^{\prime} 55^{\prime \prime} \mathrm{N}, 022^{\circ} 48^{\prime}\right.$ 33"E), 8 May 2019 G.J. Holloway \& D.E. Bakaloudis leg., 6 males and 2 females. Voucher specimens are lodged in the BNHM (1 male and 1 female) and GJHPC (1138-1148).

By far the commonest species found was $A$. verbasci (Linneaus, 1767) (1,823 individuals). Note was taken of the plants from which Anthrenus were collected. It was very clear that the insects preferred to feed as adults on white flowers, particularly Hemlock (C. maculatum), Hoary Cress (L. draba), but also Water Dropwort (Oenanthe L.) and, in woodland, Hartwort (Tordylium L.). The only time they were found on non-white flowers was when there were no white flowers available. In this instance, they were found on Woad flowers (Isatis tinctoria L.), which are yellow.

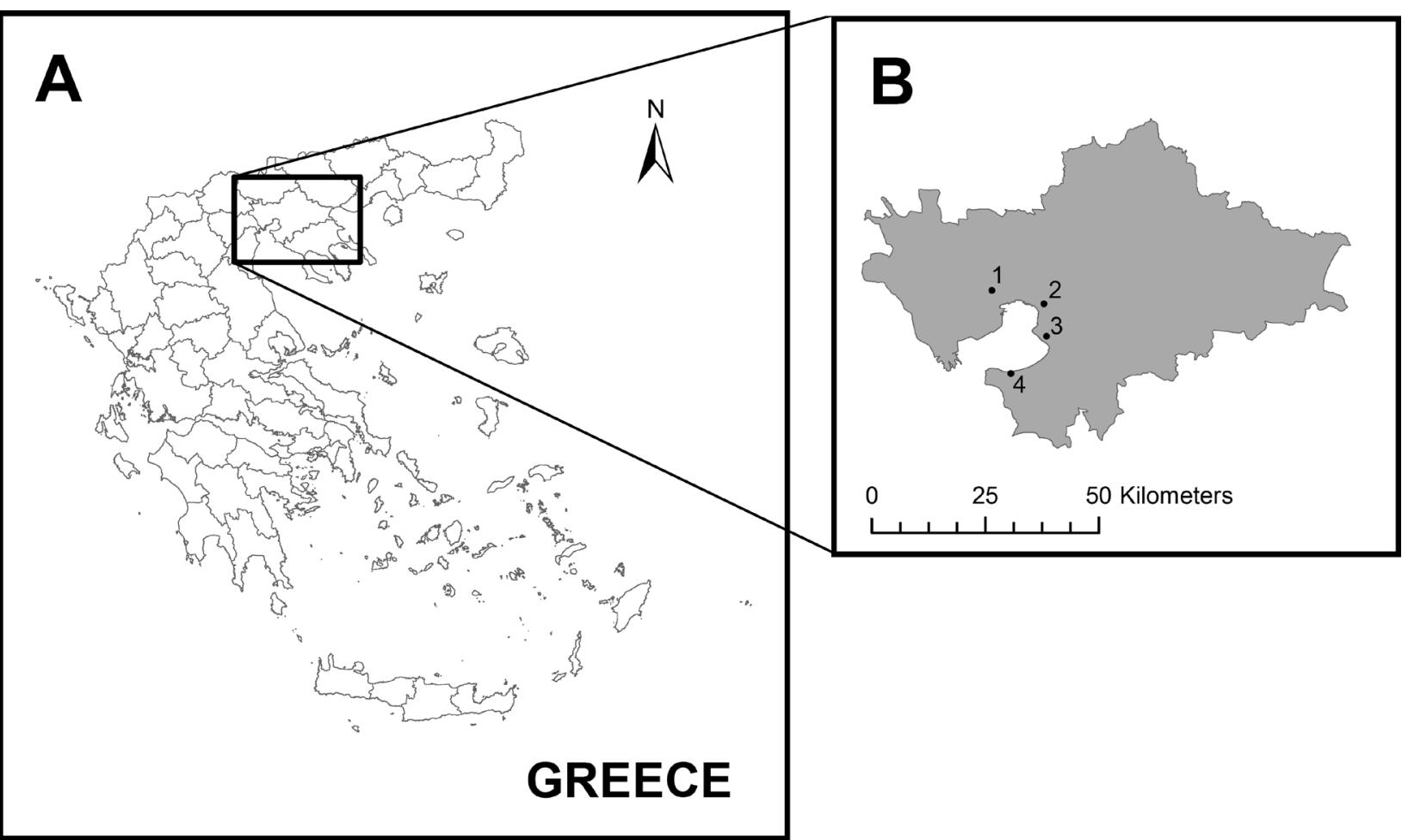

Figure 1. Map of Greece with an expansion of the Prefecture of Thessaloniki indicating the four collection sites around Thessaloniki. The sites were 1: Sindos ( $\left.40^{\circ} 39^{\prime} 55^{\prime \prime} \mathrm{N}, 022^{\circ} 48^{\prime \prime} 33^{\prime \prime} \mathrm{E}\right), 2$ : Kedrinos Lofos, Thessaloniki $\left(40^{\circ} 38^{\prime} 16.26^{\prime \prime} \mathrm{N}, 022^{\circ} 57^{\prime} 54.67^{\prime \prime} \mathrm{E}\right), 3$ : School of Forestry \& Natural Environment, Thessaloniki $\left(40^{\circ} 34^{\prime} 03.06^{\prime \prime} \mathrm{N}, 022^{\circ} 58^{\prime} 14.94^{\prime \prime} \mathrm{E}\right)$, and 4: Perea $\left(40^{\circ} 29^{\prime} 56.01^{\prime \prime} \mathrm{N}, 022^{\circ} 53^{\prime} 14.25^{\prime \prime} \mathrm{E}\right)$. 

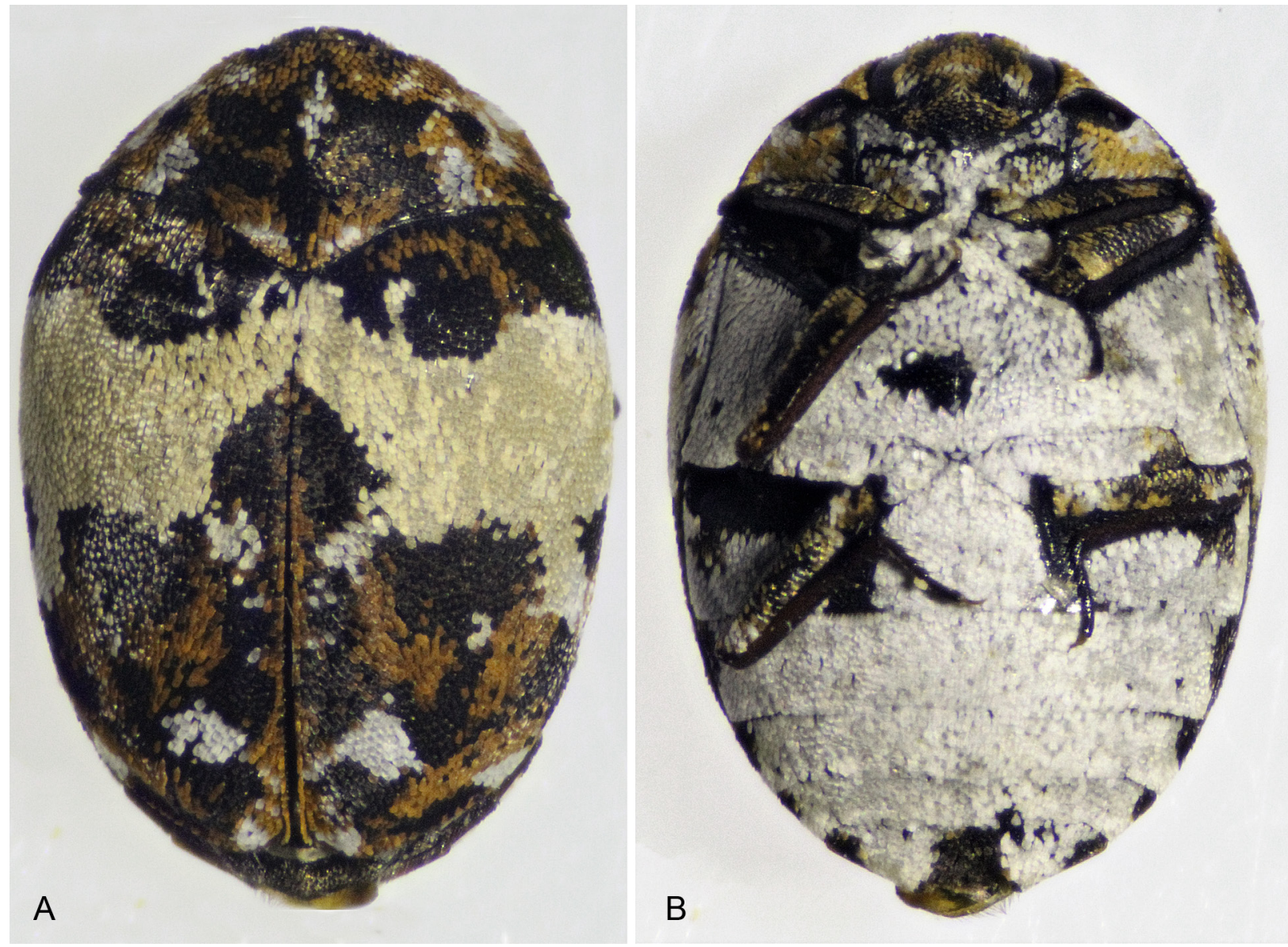

Figure 2. Habitus male Anthrenus dorsatus Mulsant \& Rey, 1868, Sindos, Thessaloniki, Greece, 8 May 2019. A. Dorsal. B. Ventral.

Identification. Anthrenus dorsatus was described in detail by Holloway et al. (2019). Identification was confirmed using a combination of characters. The ventrites shown by Holloway et al. (2019) feature large dark spots at the outermost edge of ventrite I. This feature is less evident here (Fig. 2B). Realible features are the characteristic structure of sternite IX (Kadej et al. 2007) (Fig. 3A) and the antennae (Kadej et al. 2007; Herrmann 2019) (Fig. 3B). Sternite IX of A. dorsatus has flaps folding inwards across the anterior sternite projections. The shape of the posterior end of sternite IX and the distribution of marginal setae closely match the illustration provided by Kadej et al. (2007) and the images by Holloway et al. (2019). The 11-segmented antennae have relatively broad, slightly asymmetric, 3-segmented clubs displaying wide sutures between segments 9, 10, and 11 (Fig. 3B; Kadej et al. 2007). The structure of the aedeagus (Fig. 4) closely matches the illustrations and images shown by Kadej et al. (2007), Holloway et al. (2019), and Herrmann (2019). The parameres of the aedeagus are broad, and the tip of the median lobe is very narrow. Body length (from leading edge of pronotum to tip of elytra) ranged from $2.70 \mathrm{~mm}$ to $3.70 \mathrm{~mm}$ with an average body length of $3.04 \mathrm{~mm}$. There was no significant difference between male and female body length. Figure 5 shows the female bursa copula.

Kadej et al. (2007) examined a number of species
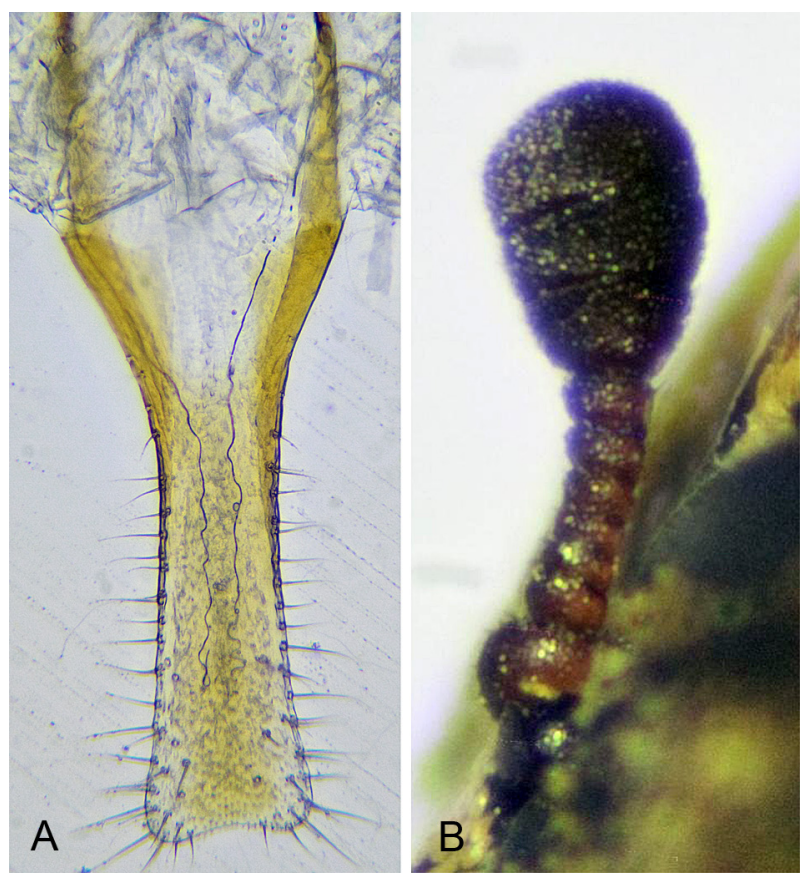

Figure 3. Sternite IX (A) and antenna (B) of Anthrenus dorsatus Mulsant \& Rey, 1868, Sindos, Thessaloniki, Greece, 8 May 2019. Note the flaps folding inwards across the anterior sternite projections, the shape of the base, and the distribution of marginal setae. The antennal club is asymmetric with wide sutures separating the antennal segments. 


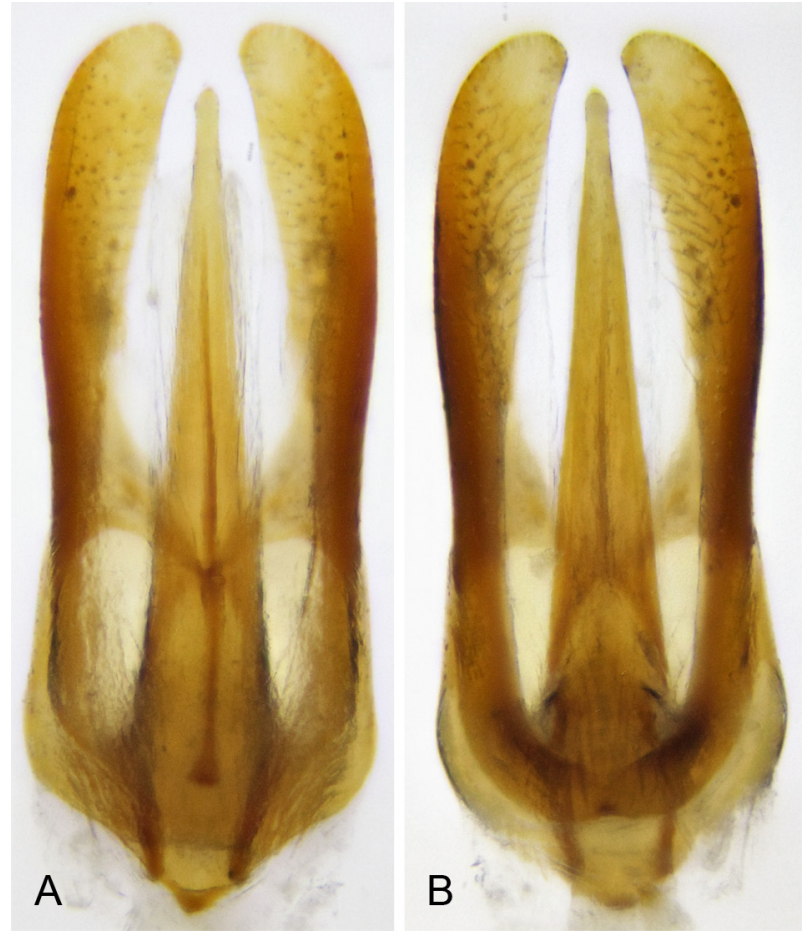

Figure 4. Aedeagus Anthrenus dorsatus Mulsant \& Rey, 1868, Sindos, Thessaloniki, Greece, 8 May 2019. A. Ventral view. B. Dorsal view.

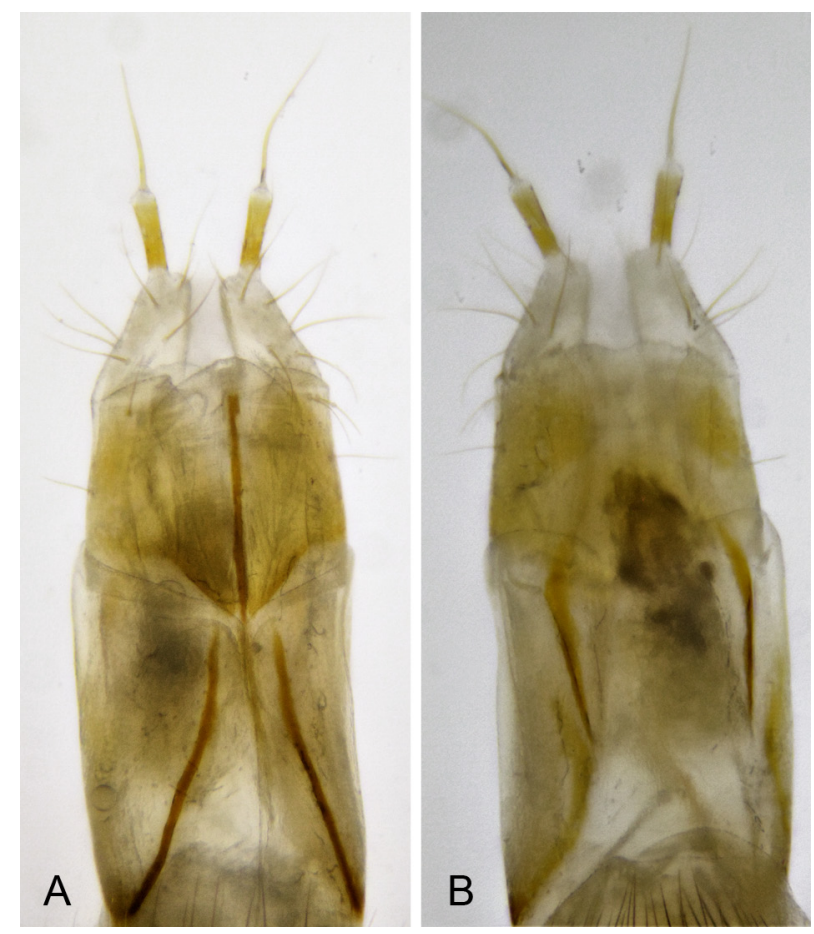

Figure 5. Bursa copula of female Anthrenus dorsatus Mulsant \& Rey, 1868, Sindos, Thessaloniki, Greece, 8 May 2019. A. ventral. B. dorsal.

from the $A$. pimpinellae complex, including $A$. dorsatus and $A$. goliath, providing illustrations to differentiate between species. Evidence suggests that the habitus of the two species is similar. The easiest way of distinguishing between $A$. dorsatus and $A$. goliath is by examining the male genitalia (images of female genitalia are not available) and antennal structure. According to Kadej et al. (2007), A. goliath sternite IX is broader throughout than $A$. dorsatus sternite IX and does not display the flaps folding over the anterior projections that are characteristic of $A$. dorsatus. The aedeagus of $A$. goliath differs structurally from that of $A$. dorsatus in having the tips of the parameres less hooked. Finally, the antennal club of $A$. goliath is very slim compared to that of $A$. dorsatus (Kadej et al. 2007).

\section{Discussion}

Much of the research being carried out on Dermestidae in recent years has been in museum collections. This has extended our knowledge of the number of Dermestidae taxa, now over 1,600 species (Háva 2015), but has offered little to our understanding of the current distributions of species. Climate change is occurring at pace and has been for many decades (Semenov and Stratonovitch 2010). It is known that the ranges of many species have changed (Pearson and Dawson 2003), so it is very likely that the ranges dermestid species have also changed. Museum collections generally contain specimens collected many years ago and seldom offer contemporary information. Foster and Holloway (2015) have argued that the range of $A$. angustefasciatus Ganglbauer, 1904 is changing in the face of climate change, and it is possible that the range of $A$. dorsatus is likewise changing, spreading north into Europe from North Africa, west towards the Iberian Peninsula and east into Greece (current study). An alternative explanation is that $A$. dorsatus has been in Greece for a long time and entomologists have only recently become aware of it. There are still only a few records of $A$. dorsatus in the literature, but where locations has been provided, they have always been from coastal regions around the Mediterranean: Tangier (Morocco) (Háva 2015c), Tunis (Tunisia) (Háva 2015b), Malta (Háva and Mifsud 2006), Pollença (Mallorca) (Holloway et al. 2019), and now also Thessaloniki (Greece). More work is needed to establish whether the distribution of $A$. dorsatus is genuinely restricted to the coast around the Mediterranean.

Museum studies also tend to consider individual specimens offering no opportunity to consider levels of intra-specific variation. Kadej et al. (2007) did study many individuals and produced size ranges for a several species. Holloway (2019) and Holloway et al. (2019) also carried out studies at the population-level, although involving fewer individuals than were studied by Kadej et al. (2007). These three studies are exceptions to the rule. Holloway et al. (2019) reported A. dorsatus from Mallorca with a body range of 2.34-3.54 $\mathrm{mm}$. This range conforms well with the body size range reported here (2.70-3.70 mm).

Dermestidae were only collected from white flowers, except when no white flowers were in the vicinity and only then were specimens found on yellow flowers. This confirms the observations made by Holloway (2019) and Holloway et al. (2019) in Mallorca where, again, dermestids were only found on white flowers. In Mallorca, 


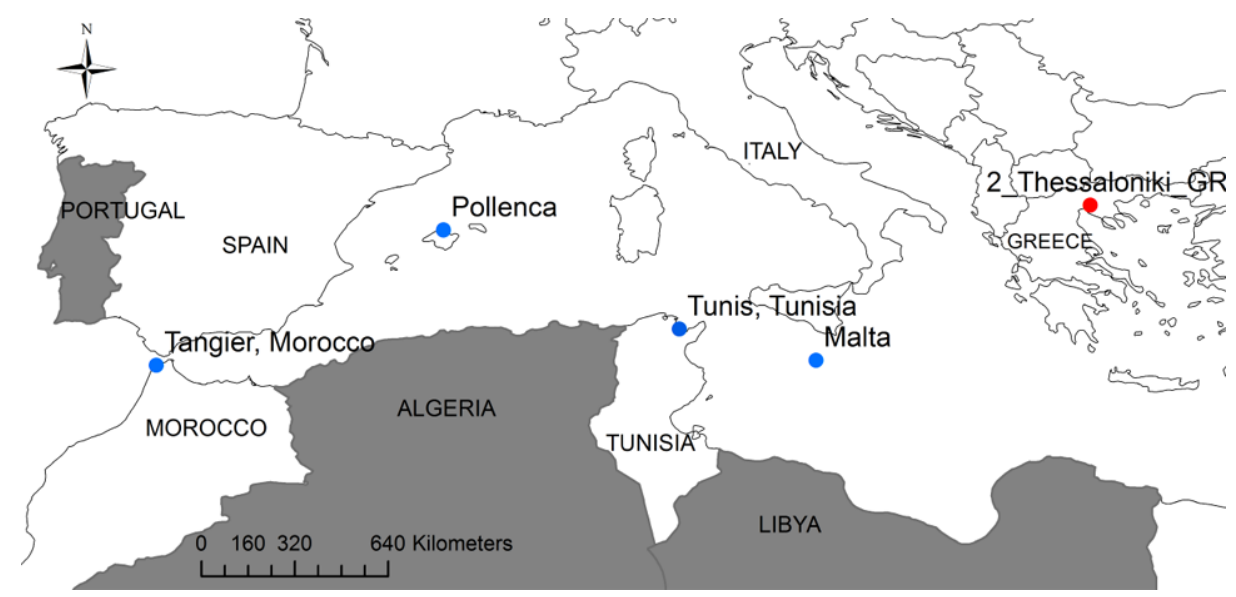

Figure 6. Mediterranean region illustrating records of Anthrenus dorsatus. The blue dots show locations of records where known; the red dot shows the site of records from the current study. Shaded areas illustrate countries from where A. dorsatus is known but specific locations are not provided in the literature.

Anthrenus, Globicornis, and Orphilus were all collected from wild carrot, Dorcus carota L. It is not known why Anthrenus are so closely associated with white flowers in the field.

Images of the female bursa copula are shown in Figure 5. Images of dermestid bursa copulae are rare (but see Kulkarni et al. 2015), and, as far as we know, there are no published images of Anthrenus female genitalia. As a result, there is nothing to compare the structure with. Whilst male genitalia are usually used in insect taxonomy (Song and Bucheli 2010), the structure of female genitalia is not without value (Lackner and Tarasov 2019). We are in the process of learning how to best identify species belonging to the Anthrenus pimpinellae complex. The most definitive anatomical characters are currently internal, but focus so far has been exclusively on males. In field collections, sometimes only females are found, so it makes sense to have as many characters as possible to aid identification. Characters on the bursa copula that are likely to be of value include the shape of the sternite plates, the shapes of the sclerotinised features on both the ventral and dorsal sides, and the distribution of the setae, in particular on the gonocoxites.

The record described here represents the most easterly report of $A$. dorsatus in Europe to date.

\section{Acknowledgements}

We are very grateful to the referees and editor for their very constructive comments on how to improve the manuscript.

\section{Authors' Contributions}

GJH and DEB collected the data. GJH wrote the text, proof-read, supplemented and modified by DEB. DEB provided the maps.

\section{References}

Foster CW, Holloway GJ (2015) Anthrenus (Anthrenus) angustefasciatus (Coleoptera: Dermestidae), a species new to Britain. British
Journal of Entomology and Natural History 28: 47-51.

Háva J (2003) World catalogue of the Dermestidae (Coleoptera). Studie a Zprávy Oblastního Muzea Prahavýchod v Brandýse nad Labem a Staré Boleslavi, Supplementum 1: 1-196.

Háva J (2015a) World catalogue of insects. Vol. 13. Dermestidae (Coleoptera). Leiden, Brill. xxvi +419 pp.

Háva J (2015b) Review of Dermestidae (Coleoptera: Bostrichiformia) deposited in the Museo Civico di Scienze Naturali Trieste. Studies and Reports Taxonomical Series 11 (2): 247-266.

Háva J (2015c) Dermestidae (Coleoptera) preserved in collection J. Volák in the East Bohemian Museum in Hradec Králové. Act Musei Reginaehradecensis S.A. 35: 53-60.

Háva J, Herrmann A (2009) New faunistic records of Dermestidae (Coleoptera) - part 3. Latyijas Entomologs 47: 3-5.

Háva J, Mifsud D (2006) The dermestid beetles (Coleoptera: Dermestidae) of the Maltese Archipelago (Central Mediterranean). Studies and Reports of the District Museum Prague East Taxonomical Series 2 (1-2): 51-63.

Herrmann A (2019) Dermestidae. http://dermestidae.com/. Accessed on: 2019-6-8.

Holloway GJ (2019) Anthrenus (s. str.) amandae (Coleoptera: Dermestidae): a new species from Mallorca, Spain. Zootaxa 4543 (4): 595-599. https://doi.org/10.11646/zootaxa.4543.4.9

Holloway GJ, Foster CW, Callaghan A (2019) New distributional record of Anthrenus dorsatus Mulsant \& Rey, 1868 (Coleoptera, Dermestidae) on the Island of Mallorca, Spain. Checklist 15 (1): 33-36. https://doi/10.15560/15.1.33

Kadej M, Háva J, Kalik V (2007) Review of the Anthrenus pimpinellae species group from Palaearctic region (Coleoptera: Dermestidae: Anthrenini). Genus 18 (4): 721-750.

Kadej M, Háva J (2011) Three new species of Anthrenus pimpinellae species group from Palaearctic Region (Coleoptera: Dermestidae: Megatominae: Anthrenini). Studies and Reports Taxonomical Series 7 (1-2): 241-248.

Lackner T, Tarasov S (2019) Female genitalia are moderately informative for phylogenetic inference and not concerted with male genitalia in Saprininae beetles (Coleoptera: Histeridae). Systematic Entomology 44 (4): 667-685. https://doi.org/10.1111/syen.12346

Mroczkowski M (1968) Distribution of the Dermestidae (Coleoptera) of the world with a catalogue of all known species. Annales Zoologici 26: 15-191.

Pearson RG, Dawson TP (2003) Predicting the impacts of climate change on the distribution of species: are bioclimatic envelope models useful? Global Ecology and Biogeography 12 (5): 361371. https://doi.org/10.1046/j.1466-822X.2003.00042.x

Semenov MA, Stratonovitch P (2010) Use of multi-model ensembles from global climate models for assessment of climate change impacts. Climate Research 41 (1): 1-14. https://doi.org/10.3354/cr00836 